\title{
La Iglesia, sacramento universal de salvación. La mediación salvífica de la Iglesia
}

\author{
Ramón Obdulio Lara Palma ${ }^{1}$
}

Recibido en 22 septiembre de 2016, aceptado el $1^{\circ}$ de noviembre de 2016

\begin{abstract}
Resumen
El autor intenta explicar la identidad de la Iglesia como sacramento universal de salvación, o sea, comprender la Iglesia como signo e instrumento de la unión de los hombres con Dios, de los hombres entre sí y de los hombres con la creación. Esa triple relación permite al mismo tiempo definir lo que la fe cristiana comprende como salvación: la vida que sólo se encuentra en la unión con Dios y la comunión que debe ser plena con los demás y con la misma creación. La argumentación pasa por dar una valoración a los ejes con los que la sacramentalidad de la Iglesia se desdobla: los siete sacramentos. Al final el lector podrá comprender que la salvación es un don sobrenatural y al mismo tiempo una tarea que la Iglesia debe cumplir como expresión de su misma identidad.
\end{abstract}

Palabras claves

Iglesia, sacramentos, salvación, comunión, vida, servicio.

\begin{abstract}
The author tries to explain the identity of the Church as universal sacrament of salvation, that is, to understand the Church as the sign and instrument of the union of men with God, of men among themselves and men with creation. This triple relationship allows at the same time to define what the Christian faith understood as salvation: life found only in union with God and the communion which must be full with others and with creation itself. The argument goes through giving an assessment to the axes with which the sacramental nature of the Church unfolds: the seven sacraments. At the end the reader will be able to understand that
\end{abstract}

1. Licenciado en Teología Dogmática por la Pontificia Universidad Gregoriana, Roma. Profesor del Seminario Mons. Óscar A. Romero, Santiago de María, El Salvador. ramon.lara@udb.edu.sv 
salvation is a supernatural gift and at the same time a task that the Church must fulfill as an expression of their own identity.

Keywords

Church, sacraments, salvation, communion, life, service.

\section{Introducción}

«La Iglesia es el pueblo de Dios neotestamentario, fundado por Jesucristo, estructurado jerárquicamente, que sirve a las exigencias del dominio de Dios y a la salvación de los hombres, y que existe como cuerpo místico de Cristo»². Más precisamente, la Iglesia es Pueblo de Dios $^{3}$ que existe como cuerpo de Cristo para ser en el mundo sacramento de salvación. ¿Cómo actúa la Iglesia esa salvación que de la cual ella es portadora? Llanamente podemos decir que, sobre todo y principalmente, bajo dos acciones concretas: sirviendo a la vida y posibilitando la comunión.

El aporte que ha ofrecido la reflexión teológica latinoamericana -a partir de la lectura conetextualizada del Concilio Vaticano II y de una hermenéutica bíblica también contextualizada - es que la salvación, de la cual la Iglesia es portadora, se identifica con la liberación integral del hombre y de la historia. Tal liberación puede ser equiparada a su vez con los conceptos «vida»y «amor», o bien, con «vivificación» $y$ «comunión» - teniendo en cuenta que sólo el amor unifica-. Somos liberados en cuanto que somos trasladados desde la condición de enemistados con Dios «lejos de su rostro» (Sal 51,13), para estar en comunión con Él «contemplando su rostro» (Sal 11,7): Coram Deo. O mejor, somos trasladados de la muerte a la vida, del aislamiento a la perfecta comunión, del pecado a la gracia. Con razón el Concilio Vaticano II ha definido la salvación como la «comunión de los hombres con Dios y comunión de los hombres entre

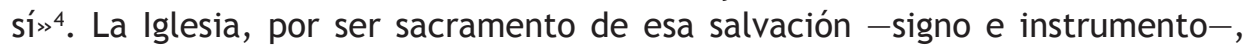
tiene la tarea de unir a todos los hombres - y todo el hombre - con Dios (vida) y unir a todos los hombres entre sí (comunión fraterna).

Esta misión de ser sacramento de salvación, o bien, la misión de unir a los hombres con Dios y a los hombres entre sí, le viene a la Iglesia por su relación íntima con la Trinidad: Ecclesia de Trinitate. Indudablemente la Iglesia tiene su origen en la Trinidad, posee una forma trinitaria y tiene su destino en la misma Trinidad. El Dios que se nos ha revelado como Trinidad se identifica como el

2. R. SCHNACKENBURG-J. DUPONT, «Boletines. La Iglesia como pueblo de Dios», Concilium 1(1965) 106.

3. La expresión «Pueblo de Dios» usada en este estudio presupone toda la eclesiología del capítulo II de la Lumen Gentium, a la que nos remitimos. Cfr. Y. CONGAR, «La Iglesia como pueblo de Dios» en Concilium, Revista internacional de teología 1(1965) 9-33; R. SCHNACKENBURG-J. DUPONT, «Boletines. La Iglesia como pueblo de Dios», Concilium 1(1965) 105-113; J. RATZINGER, El nuevo pueblo de Dios, Barcelona: Herder, 1972 [1969].

4. LG., n. 1. 
Dios de la vida y del amor: fuente de la vida plena y de la comunión perfecta. La Iglesia va en gozosa peregrinación actuando la misma obra salvadora de Cristo en el dinamismo del reditus intratrinitario, pero ahora bajo la fuerza del Espíritu Santo, hasta alcanzar la vida plena y la comunión perfecta.

Las siguientes reflexiones intentarán puntualizar en qué sentido y en qué modo la Iglesia puede actuar esa salvación en el aquí y el ahora de nuestra historia. Podremos verificar que la eclesiología sacramentaria no anula los empeños históricos, no se desatiende de las aflicciones concretas de los fieles, sino que, como teología viva, trata de iluminar las realidades palpitantes dentro de las cuales se mueve la Iglesia. Además, podremos constatar que la sacramentaria «in specie» encuentra una luz nueva para resituar y esclarecer la función de los sacramento dentro de la Iglesia. Ya que los siete signos sacramentales condensan de modo muy preciso y elocuente la manera como la Iglesia continúa la obra salvadora de Cristo.

\section{Pueblo de Dios al servicio de la vida}

«Yo he venido para que tengan vida y la tengan en abundancia» (Jn 10,10). Pero esta vida debe ser comunicada, cuidada y servida. Entendiendo vida, obviamente, como la experiencia de profunda comunión con Dios: vida en plenitud. Es una vida que, incluyendo el aspecto histórico-biológico, tiene el rasgo de ser trascendente y supra histórica, por eso divina. La Iglesia es fuente de esa vida y a la vez es su servidora. Es fuente en cuanto que la gracia vivificante de Dios fluye en ella como la sabia fluye en la corteza del árbol. Ser injertados en la vida de la Iglesia es ser injertados en la vida divina. La Iglesia es servidora de la vida divina en cuanto que tiene la misión de ofrecer los medios necesarios para que esa vida sea nutrida, curada y comunicada.

Esos medios pueden ser identificados particularmente en los sacramentos y demás celebraciones de la Iglesia; en la vida moral que es guiada por los mandamientos y particularmente por la caridad; además, en la vida interior que busca el diálogo comunicativo con Dios en la oración. Pero esos medios son al mismo tiempo la misma vida interna de la Iglesia: pues no hay Iglesia sin la liturgia (sacramentos), sin la caridad y sin la oración ${ }^{5}$. Por tanto, la Iglesia tiene una vida interior que debe ser cuidada. Centrémonos, pues, brevemente en la dimensión litúrgico-ritual de la vida de la Iglesia, para luego analizar el modo como la comunidad mesiánica ${ }^{6}$ actúa la salvación cuando celebra los ritos sacramentales.

5. Cfr. Hc 2, 42-47. Cfr. también J. A. FITZMYER, Los hechos de los apóstoles, I, Salamanca: Sígueme, 2003, 363-371.

6. A lo largo de este estudio también utilizaremos la expresión "Pueblo Mesiánico" o "Comunidad Mesiánica" siguiendo las intuiciones de Yves Congar, quien prefiere llamar a la Iglesia con esos títulos a partir de la eclesiología del No. 9 de la Lumen Gentium. Cfr. Y. CONGAR, Un pueblo mesiánico, 108. 
Con el término rito se pretende resumir el esencial accionar salvífico que se realiza en la Iglesia por ser ella continuadora de la salvación obrada por Cristo. Hay que tener en cuenta que el rito no sólo se reduce a un esquema que guía una celebración religiosa, sino que implica todo el conjunto de acciones -sean estas simbólicas, biológicas o sacramentales- que en su globalidad dan sentido a la existencia humana7. La actual teología sacramentaria está redescubriendo el papel del rito dentro de la vida de la Iglesia, con el propósito de revitalizar el rol de los signos sacramentales que manifiestan lo esencial del accionar salvífico realizado por la Iglesia ${ }^{8}$. La necesidad de pasar de unos ritos descontextualizados, ahistóricos y lejanos a la vida concreta de la gente es un imperativo tomado muy en serio en los últimos tiempos?

Puesto que el centro de los nuevos planteamientos de la teología sacramentaria está en la recuperación del rito, los sacramentos son comprendidos ahora in genere ritus. Ya no sólo se habla de «forma verbal», sino de «forma ritual»; es decir, una acción ritual contextualizada ${ }^{10}$. Se quiere con ello superar el minimalismo ritual y el formalismo rubricista que hace de las celebraciones rituales una experiencia insignificante. Los nuevos planteamientos insisten en que el rito sacramental debe recoger el contexto vital en que vive el cristiano y revitalizar los empeños concretos que éste realiza en medio de las faenas del mundo ${ }^{11}$. Ya que

\begin{abstract}
Incluso entre los mismos practicantes, es fácil verificar la esquizofrénica separación entre sacramento y vida, entre rito y compromiso, celebración litúrgica y ética social. Por lo que fácilmente el sacramento se reduce a mero rito, a mundo paralelo, a participación mecánica, a tradición o costumbre sin referencias e incidencias vitales ${ }^{12}$.
\end{abstract}

7. La acción ritual es algo originario, fundamental, en la existencia humana. Hoy se distingue un actuar representativo, simbólico, que carga de sentido la existencia, y un actuar práctico que sólo satisface las necesidades primarias y básicas de la vida biológica. Pero hay otras acciones que están en la frontera de estas dos. Son acciones que tienen una profunda carga simbólica-existencial pero que son acciones concretas de la vitalidad humana. Estas serían las acciones rituales sacramentales. Las acciones rituales devienen acciones sacramentales porque manifiestan visiblemente una identidad más profunda, es decir, la gracia de Dios que actúa y se manifiesta mediante representaciones concretas y tangibles, constatables en el cotidiano vivir. Cfr. A. GRILLO, "L'azione rituale, ovvero "ció che precede e sopravanza la ragione" ", en G. TANGORRA-M. VERGOTTINI, eds., Sacramento $e$ azione, Milano: Glossa, 2006, 179-192.

8. Cfr. A. GRILLO, Grazia visibile, Grazia vivibile. Teologia dei sacramenti «in gere ritus», Padova: Messaggero, 2008; F. GIACCHETTA, ed., Grazia Sacramentalitá Sacramenti, Assisi: Cittadella Editrice, 2008; G. TANGORRA-M. VERGOTTINI, eds., Sacramento e azione; A. GRILLO-M. PERIONI-P.-R. TRAGAN, eds., Corso di Teología Sacramentaria, I-II, Brescia: Queriniana, 2000.

9. Cfr. K. PECKLERS, Liturgia en Contexto, Caracas: Paulinas, 2007, 119; C. GIRAUDO, In unum corpus. Trattato mistagogico sull 'eucaristia, Milano: San Paolo, 2001, 597-604.

10. Cfr. A. GRILLO, Grazia visibile, Grazia vivibile. Teologia dei sacramenti «in gere ritus», 82-87.

11. Cfr. D. BOROBIO, Sacramentos y etapas de la vida, Salamanca: Sígueme, 2000, 13-64.

12. Ibid., 15. 
Separar la liturgia de la vida, entendiendo liturgia como la celebración de la fe, ha colaborado en la «ruptura entre evangelio y cultura, que es sin duda alguna el drama de nuestro tiempo» ${ }^{13}$.

Dado que la Iglesia continúa la misión y la acción salvadora de Cristo, como sacramento del mismo Señor, entonces los siete signos que acompañan la vida del cristiano se convierten en la proyección histórica de los actos esenciales de Cristo salvador ${ }^{14}$. Esta ritualidad, o sea, este accionar salvífico actuado en el hoy de la Iglesia puede sintetizarse en las nociones: iniciar, sanar y servir ${ }^{15}$. El catecismo de la Iglesia organiza el septenario sacramental bajo la ya clásica triada: sacramentos de iniciación, sacramentos de curación y sacramentos de servicio $^{16}$. Esta triada puede fácilmente identificarse con lo que según Yves Congar, fue el accionar salvífico de Cristo: acoger -entendiendo el hecho de la acogida como la intención de iniciar al hombre en una vida de comunión con Dios-, sanar y establecer nuevas relaciones ${ }^{17}$.

\subsection{Iniciar a la vida: unir al hombre con Dios}

Cuando Cristo acoge a los pecadores y excluidos del reino, realiza con ellos un camino de iniciación a la vida divina: une al hombre con Dios. Así como los que se encontraron con Jesús quedaron sumergidos en la vida divina y fueron configurados con Cristo, así también los bautizados que entran a la vida de la Iglesia, quedan configurados con Cristo y son sumergidos en esa vida divina. Los que se encontraron con Jesús y fueron acogidos por Él fueron también colmados con el don de lo alto, el Espíritu del amor, que los confirmó como auténticos hijos en el Hijo; los acogidos en la Iglesia son ungidos (crismados) para confirmar la presencia del Espíritu que los convierte en verdaderos hijos de Dios e hijos de la Iglesia. Por último, Jesús comparte la mesa con aquellos excluidos para

13. PABLO VI, Evangelii Nuntiandi, 20.

14. La idea de «actos esenciales salvíficos» realizados por Jesús, era ya insinuada por Edward Schillebeeckx, cuando hablaba de los «actos humanos salvíficos» realizados por Jesús, los que a su vez constituyen la esencia de los siete sacramentos. Cfr. E. SCHILLEBEECKX, Cristo, Sacramento del encuentro con Dios, San Sebastián: Dinor, 1963, 71. Rahner, por su parte, hace la extrapolación de esta idea hacia la Iglesia, cuando afirma que «los sacramentos son las esenciales realizaciones de la Iglesia misma». Cfr. K. RAHNER, La Iglesia y los Sacramentos, Barcelona: Herder, 1967, 23. En las palabras introductorias Rahner había afirmado: «En la intención del presente análisis, estos dos conceptos - el de Iglesia y los Sacramentos- se deben iluminar recíprocamente, de tal manera que se llegue a comprender más profundamente a la lglesia al preguntarse qué son en realidad los sacramentos y, por otra parte, se logre una mayor comprensión de estos al considerar qué es en realidad la Iglesia», Ibid., 9. Cfr. también R. ARNAU, Tratado general de los sacramentos, Madrid: BAC, 1994, 31.

15. La sistematización de la sacramentaria que ofrecen A. GRILLO-M. PERIONI-P.-R. TRAGAN, eds., en Corso di Teologia Sacramentaria, II, 95-444, los autores dividen el tratamiento de los sacramentos in specie bajo los ejes: «Confesar la fe en la vida: la iniciación cristiana», «Curar la vida: anunciar la misericordia y la resurrección» y «Promover la vida: edificar la comunidad».

16. Cfr. CEC, nn. 1212-1666.

17. Cfr. Y. CONGAR, Un pueblo mesiánico. La Iglesia sacramento de salvación, Madrid: Cristiandad, $1976,153-165$. 
mostrarles la total compenetración de vida entre el que es acogido y su persona, Cristo y el cristiano forman un solo cuerpo; también el bautizado y confirmado por la Iglesia comparte la mesa eucarística para consolidar su identidad de ser miembro vivo del cuerpo de Cristo, que es esa misma Iglesia.

\section{El catecismo sintetiza diciendo que}

mediante los sacramentos de la iniciación cristiana, el Bautismo, la Confirmación y la Eucaristía, se ponen los fundamentos de toda vida cristiana. "La participación en la naturaleza divina que los hombres reciben como don mediante la gracia de Cristo, tiene cierta analogía con el origen, el crecimiento y el sustento de la vida natural. En efecto, los fieles renacidos en el Bautismo se fortalecen con el sacramento de la Confirmación y finalmente, son alimentados en la Eucaristía con el manjar de la vida eterna, y, así por medio de estos sacramentos de la iniciación cristiana, reciben cada vez con más abundancia los tesoros de la vida divina y avanzan hacia la perfección de la caridad"18.

Pero esta vida ritual-sacramental debe hacerse además existencial ${ }^{19}$. En tal sentido, el episcopado latinoamericano reunido en la quinta conferencia (Aparecida-Brasil), fundamenta todo el tejido conceptual del documento conclusivo bajo las líneas teológicas de la cristología de la vida y la eclesiología del encuentro $^{20}$. La vida resulta ser el concepto guía de todo el documento: la vida en Cristo mediada por la Iglesia ${ }^{21}$. La primera parte es titulada: «La vida de nuestros pueblos hoy», que corresponde al paso metodológico del «ver»; la segunda: «La vida de Jesucristo en los discípulos misioneros», correspondiendo al paso del «juzgar»; y la tercera: «La vida de Jesucristo para nuestros pueblos», que corresponde al paso «actuar». Según Aparecida, el acceso a la vida en Cristo

18. CEC, n. 1212. Cfr. también D. SARTORE, «I sacramenti dell'iniziazione cristiana» en R. FISICHELLA, dir., Catechismo della Chiesa Cattolica, Casale Monferrato: Edizioni Piemme, 2003, 866: «Bautismo, confirmación y eucaristía son considerados los sacramentos de la iniciación cristiana porque constituyen los fundamentos de la vida cristiana, en cuanto introducen completamente a los hombres en el misterio de Cristo y de la Iglesia».

19. Cfr. L. BOFF, Los sacramentos de la vida, Santander: Sal terrae, 1991, 95: «El sacramento exige compromiso. Por lo demás la palabra "sacramentumn" significaba ya para los primeros cristianos de lengua latina, exactamente un compromiso, compromiso de cambio en la praxis, conversión que no era sólo una apropiación de nuevas convicciones acerca de Dios, del destino del hombre o de la esperanza de su liberación por medio de Jesucristo...se percibe claramente que el sacramento significa la culminación de todo un proceso de conversión, de compromiso y de servicio a la causa renovadora y liberadora de Cristo».

20. Cfr. M. GRONCHI, Trattato su Gesù Cristo figlio di Dio salvatore, Brescia: Queriniana, 2008, 791829. Cuando Gronchi analiza la cristología latinoamericana percibe como cristología dominante esa «Cristología de la vida».

21. Siendo un documento eminentemente pastoral la insistencia en el tema de la vida no es por casualidad. La preocupación por defender la vida en todas sus dimensiones incluye: la situación sociocultural (43-59), económica (60-73), socio-política (74-82), ecológica (83-87). La vida en Cristo incluye: la dignidad humana (387-390), pobreza (391-398), la justicia social (382-386), así como nuevas realidades tales como la cultura (476ss.) y la globalización (406ss.). Vale la pena revisar los numerales 347-364, que hablan de la «Misión de los discípulos al servicio de la vida plena». 
se hace mediante la Iglesia, pues ella se convierte en el lugar del encuentro con el Señor, el señor de la vida. Sólo con el encuentro con Cristo es que se puede tener vida en abundancia 22 . Además, la Iglesia como servidora de la vida tiene la misión de defenderla y cuidarla cuando sea amenazada o desatendida.

\subsection{Sanar la vida: curar alma y cuerpo}

Para Yves Congar las curaciones eran evidentes manifestaciones de la obra salvadora de $\mathrm{Cristo}^{23}$. La Iglesia continúa esa obra salvadora mediante los signos sacramentales que ahora se conocen como «sacramentos de curación» 24 . El hombre herido por el pecado necesita ser sanado y restituido a la vida plena, o sea, recobrar la amistad y cercanía de Dios. Así mismo, quien es tocado por el misterio del dolor mediante la enfermedad, necesita ser restituido a la tranquilidad de una vida sana, o al menos confortado y acompañado en ese camino de sufrimiento. Puesto que Jesús no fue indiferente ante quienes sufrían, sea por la condición de pecadores, sea por la condición de enfermos, también la Iglesia se muestra solícita ante la vida amenazada y disminuida ${ }^{25}$.

El catecismo sobre este aspecto afirma que

por los sacramentos de la iniciación cristiana, el hombre recibe la vida nueva de Cristo. Ahora bien, esta vida la llevamos en "vasos de barro" (2 Co 4,7). Actualmente está todavía "escondida con Cristo en Dios" (Col 3,3). Nos hallamos aún en "nuestra morada terrena" (2 Co 5,1), sometida al sufrimiento, a la enfermedad y a la muerte. Esta vida nueva de hijo de Dios puede ser debilitada e incluso perdida por el pecado.

El Señor Jesucristo, médico de nuestras almas y de nuestros cuerpos, que perdonó los pecados al paralítico y le devolvió la salud del cuerpo (cf Mc 2,1-12), quiso que su Iglesia continuase, en la fuerza del Espíritu Santo, su obra de curación y de salvación, incluso en sus propios miembros. Este es finalidad de los dos sacramentos de curación: del sacramento de la Penitencia y de la Unción de los enfermos ${ }^{26}$.

22. Cfr. D. VITALI, «Jesucristo camino, verdad y vida: eje transversal de Aparecida» en PONTIFICIA COMISIÓN PRO AMÉRICA LATINA, Aparecida 2007. Luces para America Latina, Vaticano: Editrice vaticana, 2008, 20-37. Según Vitali, es posible identificar la terna fe-esperanza-caridad con la terna camino-verdad-vida. Camino correspondería a la esperanza, la verdad a la fe y vida al ágape. La vida cristiana, entonces, que es fe, esperanza y caridad, es un vivir en Cristo camino, verdad y vida. Esta vida en Cristo se da sólo dentro de la Iglesia, ya que los dones de la fe, esperanza y caridad son otorgados mediante la inserción en la Iglesia, puesto que Cristo es la cabeza y comunica todos los dones y gracias a su cuerpo.

23. Cfr. Y. CONGAR, Un pueblo mesiánico, 153.

24. Cfr. CEC, nn. 1420-1532. Cfr. también PABLO VI, Sacram Unctionem (1972), la constitución apostólica que aprueba el nuevo ritual de la unción; JUAN PABLO II, Reconciliatio et Paenitentia (1984).

25. Cfr. G. FLóREZ, Penitencia y Unción de enfermos, Madrid: BAC, 1993, 358-365.

26. CEC, nn. 1420-1421. Antonio Miralles advierte que entre el sacramento de la penitencia y el 
Pero la Iglesia, sacramento de salvación, no reduce su misión sanadora a la celebración de algunas rúbricas litúrgicas. El catecismo precisa que la misión sanadora de Cristo se da en el campo del pecado y en el campo de la enfermedad corporal; la Iglesia lo hace igualmente, pero lanzada hacia derroteros más amplios, ya que ni el pecado se reduce a un acto de alcance estrictamente individual ni la enfermedad es sólo sufrimiento del cuerpo ${ }^{27}$. Además, dado que Jesús sanaba a los enfermos para confirmar la presencia de Reino de Dios y manifestar la infinita misericordia y compasión del mismo Señor, la lglesia ejerciendo su obra sanadora testifica ese Reino en el hoy de la historia y actualiza la misericordia divina ${ }^{28}$.

Curación del pecado. El pecado es una enfermedad que tiene amplias consecuencias, que van más allá del drama personal ${ }^{29}$. En tal sentido el episcopado latinoamericano ya desde 1968 había advertido de estas amplias repercusiones hablando de «estructuras injustas» ${ }^{30}$, o como Puebla precisa, de un «pecado estructural»31. Este pecado estructural se manifiesta concretamente mediante las injusticias, la explotación del pobre y del débil, así como por la marginación de grandes masas sociales. Ante una realidad en la que la vida se vea amenazada y reducida a condiciones inhumanas, es obvio que la Iglesia quiera defenderla, atacando la raíz, o sea el pecado y sus estructuras, y llamando al pecador a la conversión. 0 en otras palabras, trabajando para que el Reino de Dios que es «el reino de la verdad y la vida, el reino de la santidad y la gracia, el reino de la justicia, el amor y la paz»32, sea realmente instaurado.

Dado que la pobreza es signo de muerte, la opción por los pobres es una opción por la vida: el Dios de la vida exige vida para sus hijos ${ }^{33}$. Como el buen samarita-

de la unción existe una relación de continuidad. Además, recuerda que según Trento «toda la vida cristiana debe ser una penitencia continua» (DS, 1694), Cfr. A. MIRALLES, «L' unzione degli infermi», en R. FISICHELLA, dir., Catechismo della Chiesa Cattolica, 902.

27. Cfr. A. MARTÍNEZ SIERRA, 100 Fichas sobre temas controvertidos del sacramento de la reconciliación, Burgos: Monte Carmelo, 2008, 20-27; M. NICOLAU, La unción de los enfermos. Estudio histórico-dogmatico, Madrid: BAC, 1975, 222-234.

28. Cfr. PH. ROUILLARD, "L'unzione degli infermi e i riti funebri», en A. GRILLO-M. PERIONI-P.-R. TRAGAN, eds., en Corso di Teologia Sacramentaria, II, 363-364.

29. Cfr. JUAN PABLO II, Reconciliatio et Paenitentia (1984), 14-18.

30. Cfr. II CONFERENCIA GENERAL DEL EPISCOPADO LATINOAMERICANO, Medellín. Conclusiones: La Iglesia en la actual transformación de América Latina a la luz del Concilio, Bogotá: CELAM, 2002, Justicia, n. 2.

31. Cfr. III CONFERENCIA GENERAL DEL EPISCOPADO LATINOAMERICANO, Puebla: La evangelización en el presente y el futuro de América Latina, Bogotá: CELAM, 2000, n. 1258: «Son muchas las causas de esta situación de injusticia, pero en la raíz de todas se encuentra el pecado, tanto en su aspecto personal como en las estructuras mismas». La Reconciliatio et Paenitentia habla del «Pecado Social» en los siguientes términos: «Hablar de pecado social quiere decir, ante todo, reconocer que, en virtud de una solidaridad humana tan misteriosa e imperceptible como real y concreta, el pecado de cada uno repercute en cierta manera en los demás», n. 16.

32. Prefacio de la Solemnidad de Cristo Rey.

33. Cfr. G. GUTIÉRREZ, «Pobres y Opción Fundamental», en I. ELLACURÍA-J. SOBRINO, dirs., Mysterum Liberationis. Conceptos Fundamentales de la Teología de la Liberación, I, Madrid: Trotta, 1990, 304313; N. VÉLEZ, «Puebla: la opción por los pobres», Theologica Xaveriana 51-52 (1979) 299-307. 
no, la Iglesia se acerca al que está despojado y herido: despojado de su dignidad y herido por la injusticia. La solidaridad ante el dolor es el signo distintivo de la Iglesia ${ }^{34}$. Con razón los obispos en Medellín concluyeron en que «el Episcopado Latinoamericano no puede quedar indiferente ante las tremendas injusticias sociales existentes en América Latina, que mantienen a la mayoría de nuestros pueblos en una dolorosa pobreza cercana en muchísimos casos a la inhumana miseria» ${ }^{35}$. Puesto que el pecado es muerte, en el amplio sentido de la palabra, la Iglesia como servidora y defensora de la vida tiene en este campo una gran misión que realizar.

Curación de la enfermedad. Actuar la salvación en el terreno del dolor y la enfermedad es también misión de la Iglesia ${ }^{36}$. Claro que el sufrimiento tiene valor salvífico ${ }^{37}$. Sin embargo, la Iglesia como continuadora de la obra salvadora de Cristo sabe muy bien que el diseño originario de Dios es la vida íntegra de sus fieles, que el reino divino excluye toda forma de disminución de la vida pues esta debe vivirse en plenitud. Por eso implora al «Señor que sana» (Ex 15,20) por la salud de los enfermos. El signo sacramental que por antonomasia expresa esa solicitud de la Iglesia por el enfermo es el Sacramento de la Unción ${ }^{38}$.

Entre los efectos de la gracia que confiere este sacramento están: la unión del enfermo a la Pasión de Cristo, para su bien y el de toda la Iglesia; el consuelo, la paz y el ánimo para soportar cristianamente los sufrimientos de la enfermedad o de la vejez; el perdón de los pecados si el enfermo no ha podido obtenerlo por el sacramento de la penitencia; el restablecimiento de la salud corporal, si conviene a la salud espiritual; la preparación para el paso a la vida eterna ${ }^{39}$.

Para propiciar la experiencia de esos efectos de la gracia sacramental de la unción, la Iglesia como comunidad mesiánica no debe dejar de promover insistentemente la pastoral de enfermos y la instauración de sistemas de prevención, curación e investigación sanitaria allá donde no los haya ${ }^{40}$. Además, debe ofrecer las orientaciones ético-morales ante los nuevos panoramas de la investigación científico-genética y las demás ciencias sanitarias, pero sin apagar las legítimas iniciativas ${ }^{41}$. En otras palabras, la Iglesia tiene la misión

34. Cfr. V CONFERENCIA GENERAL DEL EPISCOPADO LATINOAMERICANO, Aparecida. Documento conclusivo, Bogotá: CELAM, 2007, 26.

35. MEDELLÍN, Paz, n. 16

36. Cfr. D. BOROBIO, Sacramentos y etapas de la vida, 274.

37. Cfr. JUAN PABLO II, Salvifici doloris (1984), n. 1.

38. Cfr. CEC., n. 1511.

39. Cfr. CEC., n. 1532.

40. M. Nicolau nos recuerda que el Vaticano II en la Sacrosanctum Concilium n. 2 enfatiza en el carácter social de los sacramentos: «El carácter social de todos los sacramentos queda manifiesto en las palabras del texto conciliar: los sacramentos están ordenados a la "edificación del Cuerpo de Cristo" y más adelante: "a ejercitar la caridad" ": M. NICOLAU, La unción de los enfermos, 172. 41. Cfr. F. J. BLÁZQUEZ-RUIZ, «Nueva genética, regulación jurídica y privacidad» en ID., dir., 10 palabras claves en nueva genética, Navarra: EVD, 2006, 31-74; D. BORORBIO, «Conciencia moral y participación litúrgico sacramental» en Phase 209 (1995) 357-384. 
de humanizar el dolor y la enfermedad, o mejor dicho, tiene la misión de cristianizar estas realidades, pues la misericordia y la compasión de Dios deben palparse en todas las áreas de la vida. El dolor y la enfermedad definitivamente ofrecen a la comunidad mesiánica un gran campo de acción.

\subsection{Servir a la vida: por la donación y el encuentro}

Yves Congar sostiene que la obra salvadora de Cristo toca el campo de las relaciones interpersonales: Cristo salva recreando profundas relaciones fraternas ${ }^{42}$.

En la vida interna de la comunidad mesiánica domina el ágape fraterno, que trasforma la autoridad en verdadero servicio en función de la comunidad y trasforma la relación entre el hombre y la mujer en una experiencia de perfecta comunión que está abierta a la vida ${ }^{43}$. Con el pasar de los siglos la Iglesia reconoció estas realidades como eventos salvíficos: sacramentos. «El Orden y el Matrimonio, están ordenados a la salvación de los demás. Contribuyen ciertamente a la propia salvación, pero esto lo hacen mediante el servicio que prestan a los demás. Confieren una misión particular en la Iglesia y sirven a la edificación del Pueblo de Dios» ${ }^{44}$.

El Sacramento del orden promueve y edifica la vida eclesial ${ }^{45}$. El Catecismo ciñe la identidad sacramental del servicio a la comunidad (Orden) al «ministerio apostólico ${ }^{46}$. El Orden es el sacramento del ministerio apostólico ${ }^{47}$. El ministerio apostólico tiene la misión de la representatividad sacramental y el ordenamiento de los carismas y ministerios dentro de la misma comunidad. Cierto que todos los bautizados participan del sacerdocio común que confiere el bautismo, pero dentro de la comunidad de bautizados surgen los que reciben la misión de participar del sacerdocio de Cristo, participando de la misión de Cristo como Cabeza y Pastor de la comunidad ${ }^{48}$.

42. Cfr. Y. CONGAR, Un pueblo mesiánico, 162-165.

43. Cfr. J. F. PUGLISI, «Il ministero Ordinato: Episcopato, presbiterato, diaconato» en A. GRILLO-M. PERIONI-P.-R. TRAGAN, eds., en Corso di Teologia Sacramentaria, II, 379-414; R. ARNAU, Orden y Ministerios, Madrid: BAC, 1995, 190-205; M. ALIOTTA, Il matrimonio, Brescia: Queriniana, 2002, 67108; G. FLÓREZ, Matrimonio y Familia, Madrid: BAC, 1995, 108-113.

44. Cfr. CEC n. 1534. La fijación dogmática de los sacramentos la encontramos cerrada hasta Trento.

Cfr. DS, 1601-1613.

45. Cfr. Cfr. J. F. PUGLISI, «Il ministero Ordinato: Episcopato, presbiterato, diaconato», 379.

46. CEC n. 1536.

47. Este ministerio apostólico se participa en modo diferenciado: «Desde los orígenes, el ministerio ordenado fue conferido y ejercido en tres grados: el de los Obispos, el de los presbíteros y el de los diáconos. Los ministerios conferidos por la ordenación son insustituibles para la estructura orgánica de la Iglesia: sin el obispo, los presbíteros y los diáconos no se puede hablar de Iglesia», CEC n. 1593. 48. R. ARNAU, Orden y Ministerios, 34: «El máximo momento en el que Cristo vincula a su propia potestad el poder que concede a los Apóstoles ocurre tras la resurrección, en el diálogo a la vez purgativo y constitucional del ministerio de Pedro, en el que Cristo le confiere ser pastor de los corderos y de las ovejas. A la vista de estas referencias se ha de concluir que los Apóstoles, por la misión recibida de Cristo, son pastores en la Iglesia». 
Este sacerdocio ministerial difiere del sacerdocio común porque confiere el poder de ejercer en nombre de Cristo, y para edificación de la comunidad, la misión de enseñar (munus docendi), celebrar el culto (munus liturgicum) y gobernar (munus regendi) ${ }^{49}$. Por medio de este sacramento la comunidad mesiánica es ordenada en sus distintos carismas y servicios que construyen y fortalecen la misma comunidad. En pocas palabras, podemos decir que el dinamismo salvífico de Cristo actuado ahora por la Iglesia en forma de diakonía tiene su cauce de realización al interno de la comunidad en el sacramento del orden. Pero la diakonía de la Iglesia que se sacramentaliza en el Orden no sólo convierte a los miembros del Orden en servidores de la koinonía del Señor, sino también en servidores del mundo: la consecratio mundi ${ }^{50}$.

Por otra parte, en cuanto servidor de la vida, el pueblo mesiánico ejerce su misión salvífica también bajo el signo de la íntima comunión de vida y amor que sus miembros comparten en la unión esponsal ${ }^{51}$. Ciertamente que el matrimonio, la sexualidad y la familia son experiencias profundamente humanas ${ }^{52}$. Sin embargo, la experiencia esponsal, aun teniendo un carácter natural y netamente humano, «fue elevada por Cristo Nuestro Señor a la dignidad de sacramento entre bautizados»53. Trento canoniza esta dignidad sacramental al indicarlo en el elenco de los siete sacramentos ${ }^{54}$. Si es sacramento, quiere decir que el matrimonio comunica la gracia salvadora de Cristo $^{55}$.

49. Cfr. LG, nn. 18-29. El Concilio hizo grandes renovaciones en el campo de la teología del ministerio y del sacramento del orden. El Decreto Christus Dominus (28 de octubre 1965) y el Presbyterorum Ordinis (7 de diciembre 1965) recogen y amplían el capitulo tres de la Lumen Gentium.

50. Los ministros ordenados, o mejor dicho la Jerarquía de la Iglesia, existe para servir y edificar la comunidad cristiana y para santificar el mundo: mediante el testimonio de caridad y de comunión fraterna. Cfr. M. R. Rodríguez, El presbiterio y la fraternidad sacerdotal, Madrid: BAC, 2008, 97113. El tema de la Consacratio mundi, o sea «la inserción del mundo en el plan de la salvación que Dios ha querido para la humanidad y para el mundo entero", es según B. Mondin uno de los ejes primordiales del pensamiento de Y. Congar. Cfr. B. MONDIN, La Chiesa primizia del regno, Bologna: Deoniano, 1986, 170.

51. Cfr. S. LOUAY, Santificazione e valore salvifico del matrimonio, Tesi PUG 1433 (2008). Louay analiza el carácter salvífico del amor esponsal según san Pablo en 1Cor 7, 12-16 y en Efesios 5, 25-33.

52. Cfr. R. TAGLIAFERRI, «Dedicare la vita: Il matrimonio e la famiglia» en A. GRILLO-M. PERIONI-P.-R. TRAGAN, eds., en Corso di Teologia Sacramentaria, II, 226-281. Tagliaferri habla de la dimensión psico-biológica y mitológica del matrimonio para luego concretizar el carácter teológico de esta experiencia humana.

53. CEC n. 1601; CIC, can. 1055,1.

54. Cfr. DS, 1601. Y particularmente los cánones sobre el matrimonio: DS, 1797-1816.

55. El enganche bíblico-teológico de este sacramento encuentra su asidero en el pasaje de Ef. 5, 32, ya retomado en Trento (Cfr. DS, 1799). Inmerso en las coordenadas cristológicas y eclesiológicas, el matrimonio se convierte en un espacio-lugar de revelación y de salvación: revela la relación Cristo-Iglesia y comunica la gracia salvadora en cuanto que la relación conyugal vive en la misma dimensión del amor divino. La Gaudium et Spes n. 48 sintetiza: "Cristo nuestro Señor bendijo abundantemente este amor multiforme, nacido de la fuente divina de la caridad y que está formado a semejanza de su unión con la Iglesia. Porque así como Dios antiguamente se adelantó a unirse a su pueblo por una alianza de amor y de fidelidad, así ahora el Salvador de los hombres y Esposo de la Iglesia sale al encuentro de los esposos cristianos por medio del sacramento del matrimonio". 
Del Matrimonio surge la familia, Iglesia doméstica, célula fundamental de la sociedad. Además, la familia cristiana representa la reserva más segura e inmediata para que la vida cristiana pueda incidir en la esfera pública: familias verdaderamente cristianas transformarán radicalmente la sociedad. Puesto que la Iglesia nació en el contexto familiar, se fundamentó bajo la estructura familiar, hoy más que nunca la comunidad mesiánica debe apostarle a la familia para continuar su misión salvífica en el aquí y ahora de la historia ${ }^{56}$. La Iglesia y la sociedad necesitan verdaderas y sanas familias cristianas, ellas son verdaderos santuarios de vida y amor.

\section{Pueblo de Dios instrumento de comunión}

El pueblo mesiánico es signo e instrumento de la comunión con Dios y de los hombres entre sí. La salvación la hemos identificado como ese dinamismo que lleva a la comunión, o más bien, la experiencia de la salvación encuentra su máxima expresión en la perfecta comunión con Dios, con los demás hombres y con la misma creación. Podemos decir, además, que la comunión de la cual la Iglesia es servidora afinca sus raíces en el humus cristológico y pneumatológico: la comunión es unidad en un solo Cuerpo (eclesiología eucarística) y es acción del Espíritu Santo (eclesiología pneumatológica) ${ }^{57}$. Es que la dimensión eucarística y pneumatológica son parte constitutiva de la identidad de la Iglesia y son indispensables en su misión sacramental y salvífica, o sea, como instrumento de esa comunión triple de la que a continuación hablaremos.

\subsection{Comunión de los hombres con Dios}

Cristo es el sacramento del encuentro con Dios. Él pontifica la íntima comunión con lo divino. La Iglesia, en Cristo, continúa esa misión: «es en Cristo como un sacramento o señal e instrumento de la íntima unión con Dios» ${ }^{58}$. La Iglesia actúa esa diaconía de comunión, como hemos podido constatar, a nivel litúrgicoritual. Los sacramentos de iniciación cristiana, sobre todo, celebrados y vividos en la Iglesia, fungen como puentes para posibilitar la comunión íntima con Dios.

Pero la misión salvífica de la Iglesia, o sea, unir al hombre con Dios, no se reduce a la celebración de los sacramentos. Yves Congar lo había afirmado muy

\footnotetext{
56. Los numerosos documentos que el magisterio contemporáneo ha emitido indican la preocupación por la realidad matrimonial y familiar. Sin embargo el trabajo en este terreno es todavía muy grande. Cfr. PIO XI, Casti Connubii (1930); CONCILIO VATICANO II, Gaudium et Spes nn. 47-52 (1965), Pablo VI, Humanae Vitae (1968); JUAN PABLO II, Familiaris Consortio (1981); ID., Carta de los derechos de la familia (1983); ID., Carta a las familias (1994); CONGREGACIÓN PARA LA DOCTRINA DE LA FE, Instrucción sobre los matrimonios mixtos (1966); COMISIÓN TEOLÓGICA INTERNACIONAL, DOCTRINA CATÓLICA SOBRE EL MATRIMONIO (1977), entre otros.

57. J. FONTBONA, Comunión y sinodalidad, Barcelona: Facultad de Teología de Catalunya, 1994, 252-256.
}

58. LG, n. 1. 
categóricamente ${ }^{59}$. Es evidente, por tanto, la presencia de otras vías que la comunidad mesiánica ofrece a los hombres para poder iniciar, profundizar y consolidar esa comunión con $\operatorname{Dios}^{60}$. Entre estas otras diversas vías podemos mencionar: el cultivo de la vida interior (la espiritualidad), la vivencia, enseñanza y defensa de los valores profundamente humanos/cristianos (la moral), y la infatigable búsqueda de comunión en un mismo credo (la comunión de fe). Mediante una auténtica espiritualidad cristiana ${ }^{61}$, una precisa moral ${ }^{62}$ y una cada vez más clara doctrina ${ }^{63}$, la Iglesia ofrece unos esenciales vehículos para entrar en esa comunión divina.

El autor principal de estas nuevas vías, y todas las que a nosotros aún son desconocidas, es el Espíritu Santo. Él es quien impulsa al hombre a buscar en lo más íntimo de su corazón para encontrarse con el mismo Dios; es el que mueve la conciencia del hombre a ceñirse a los hondos valores que perfeccionan el vivir humano; además, es el Espíritu quien ilumina la mente para profundizar cada vez más los misterios revelados y contenidos en el precioso depósito de la fe custodiado y comunicado por la comunidad mesiánica.

Pero también el pueblo mesiánico que vive esa profunda sintonía con el Espíritu, que practica los mismos valores fundamentales, que profesa una misma fe, que celebra los mismos ritos sacramentales, constituye la más genuina realidad eucarística $^{64}$. La eucaristía es el sacramento que recoge todo lo que en el pueblo

59. Y. CONGAR, Un pueblo mesiánico, 95.

60. Congar mencionaba entre otros canales: la Palabra revelada y su predicación, la oración, el testimonio de una caridad activa, etc. Cfr. Y. Congar, Un pueblo mesiánico, 95. Sin embargo, el conocimiento de todos los modos concretos por medio de los cuales Dios puede comunicarse a todos los hombres escapa al dominio cognoscitivo de la Iglesia. La Gaudium et Spes 22 reconoce humildemente: "Cristo murió por todos, y la vocación suprema del hombre en realidad es una sola, es decir, la divina. En consecuencia, debemos creer que el Espíritu Santo ofrece a todos la posibilidad de que, en la forma de sólo Dios conocida, se asocien a este misterio pascual» (el cursivo es nuestro).

61. Cfr. S. GAMARRA, Teología espiritual, Madrid: BAC, 1994, 51: «No basta el mero reconocimiento de Dios; se necesita cultivar y vivir la relación interpersonal con Dios. La espiritualidad, si es verdadera, supone una actitud contemplativa que debe ser atendida. Se trata de contemplar al verdadero Dios de Jesucristo, Dios uno y trino".

62. Cfr. J.R. FLECHA ANDRÉS, Teología moral fundamental, Madrid: BAC, 1994, 149-154. Flecha sostiene la condición de sujeto y objeto de la moral en el hombre dada su identidad de ser imagen de Dios: «Esa intrínseca e inabdicable religación del hombre a Dios [...] constituye un fundamento imprescindible para la ética cristiana", Ibid., 153. El hombre, imagen de Dios, cultivando las virtudes mediante la gracia divina alcanza su mayor semejanza con Dios: entra en comunión cada vez más perfecta con el creador.

63. Cfr. J.L. ILLANES - J.I. SARANYANA, Historia de la teología, Madrid: BAC, 1995, XVI. Los autores trazan una línea diacrónica en la investigación teológica con el propósito de señalar las huellas que la profundización de la fe ha ido dejando. Por lo que es posible afirmar que cuanto más se conoce la fe, más se encuentran puntos de convergencia que permiten una «confesión única de la fe», pues la Iglesia es también "congregatio fidelium». Es interesante también notar cómo el movimiento ecuménico ha encontrado en el campo de la profundización doctrinal un camino de comunión entre las Iglesias. El trabajo de la comisión Fe y Constitución lo demuestra. En pocas palabras, el profundizar los misterios de la fe no sólo nos une más con Dios sino que nos une más como Iglesias. 64. Cfr. PO, n. 5: «Los demás sacramentos, como también todos los ministerios eclesiales y las 
mesiánico tiene color de comunión, ya que es el banquete que prefigura «la reunión de los hombres en el reino de Dios» ${ }^{65}$. La eclesiología de la comunión es eclesiología eucarística ${ }^{66}$. Además, la Eucaristía es la fuente y la cumbre de la vida cristiana-eclesial ${ }^{67}$.

\begin{abstract}
Eucaristía y la comunión eclesial se exigen y se corresponden. Cada una es camino y condición para la otra. Se participa en la eucaristía porque se pertenece a la Iglesia y se pertenece a la Iglesia porque se participa en la eucaristía. Se comulga eucarísticamente porque se está en comunión con la Iglesia y viceversa... la eucaristía significa a la Iglesia en su ideal de unidad y de santidad ${ }^{68}$.
\end{abstract}

«La Eucaristía edifica la Iglesia y la Iglesia hace la Eucaristía»69. La insistencia en el tema eucarístico es necesaria ya que la Iglesia como gran synaxis eucarística es quien por antonomasia posibilita la comunión de los hombres con Dios: «En cada Celebración eucarística se realiza sacramentalmente la reunión escatológica del Pueblo de Dios. El banquete eucarístico es para nosotros anticipación real del banquete final, anunciado por los profetas (cfr. Is 25,6-9) y descrito en el Nuevo Testamento como "las bodas del cordero" (Ap 19,7-9), que se ha de celebrar en la alegría de la comunión de los santos ${ }^{70}$. Si la Iglesia tiene la misión de unir a los hombres con Dios, repitámoslo una vez más, mediante el misterio eucarístico lo realiza en modo supremo.

\title{
2.2. Comunión de los hombres entre sí
}

La Iglesia es también instrumento de la comunión de los hombres entre sí. El hombre que ha establecido una profunda comunión con Dios es lanzado al en-

obras de apostolado, están unidos a la Eucaristía y a ella se ordenan. La sagrada Eucaristía, en efecto, contiene todo el bien espiritual de la Iglesia, es decir, Cristo mismo, nuestra Pascua». Cfr. también Y. CONGAR, «L'Eucarestia e la Chiesa della Nuova Alleanza» en Le vie del Dio vivo, Brescia: Morcelliana, 1965, 165-183.

65. Cfr. J.M. TILLARD, «La eucaristía, sacramento de la comunión eclesial», en B. LAURET-F. REFOULE, dirs., Iniciación a la práctica de la teología, III, Madrid: Cristiandad, 1985, 422. «En el Antiguo testamento el tema de la comida estaba ligado a los dos extremos de la aventura de Yahvé con su pueblo: la conclusión de la alianza en el Sinaí por un gran "sacrificio de comunión" que sellaba el pacto (“contemplaron a Dios y luego comieron y bebieron”, Ex 24,11), el día mesiánico en que todo debía terminar en la alegría del banquete con Dios», Ibid., 321.

66. Cfr. B. FORTE, La Chiesa nell'Eucaristia per un'ecclesiologia eucaristica alla luce del Vaticano II, Napoli: D'Auria, 1975, 35.

67. Cfr. LG, n. 11: «(Los fieles cristianos) participando del sacrificio eucarístico, fuente y cima de toda vida cristiana, ofrecen a Dios la Víctima divina y a sí mismos juntamente con ella [...] Pero una vez saciados con el cuerpo de Cristo en la asamblea sagrada, manifiestan concretamente la unidad del pueblo de Dios aptamente significada y maravillosamente producida por este augustísimo sacramento».

68. D. BOROBIO, Eucaristía, Madrid: BAC, 2005, 347.

69. Cfr. JUAN PABLO II, Ecclesia de Eucharistia (2003), n. 26. «La Iglesia vive de la Eucaristía. Esta verdad no expresa solamente una experiencia cotidiana de fe, sino que encierra en síntesis el núcleo del misterio de la Iglesia», Ibid., n. 1.

70. BENEDICTO XVI, Sacramentum Caritatis (2007), n. 31. 
cuentro de su hermano. La salvación como comunión con Dios no es completa sin la comunión fraterna. La misma constitución personal del hombre le exige la comunión, pues en cuanto que es persona, no se realiza sino en la intercomunicación ${ }^{71}$.

\begin{abstract}
Para el cristiano la unidad de cada persona en sí misma y con las otras personas está producida ya radicalmente por virtud del bautismo que lo renueva en el Espíritu Santo con el don de la fe. El hombre nuevo es sólo aquel que tiene conciencia de pertenecer a Cristo, y que le pertenece juntamente con todos los demás, y quien sabe que todos los demás son parte constitutiva de él mismo, porque también ellos pertenecen a Cristo, como Cristo pertenece al Padre ${ }^{72}$.
\end{abstract}

El hombre, pues, es un ser relacional por naturaleza y por ser cristiano es además vinculado. «Creer en Dios y cerrarse, aunque sea a un hombre solo, es contradicción. "La relación del hombre para con Dios Padre y la relación del hombre para con los hombres sus hermanos están de tal forma unidas que la Escritura llega a decir: el que no ama, no ha conocido a Dios" (1Jn 4,8)»73. El vínculo que nace de la fe y se concretiza en la caridad permite al hombre construir nuevas redes de relaciones: fraternas y solidarias ${ }^{74}$.

El hombre vive en comunión. Siempre vinculado al otro. Y con el paso del tiempo ha ido modificando su convivencia social. Además, ha creado una gran diversidad de modelos sociales: desde los más simples (primitivas sociedades gregarias) hasta los más complejos (moderna sociedad funcional y tecnológica). Esta connatural dimensión societaria del hombre y la actual experiencia funcional y tecnológica, permiten reconocer un dinamismo de unificación nunca antes visto ni pensado,

71. Las diversas aproximaciones antropológicas a partir del personalismo de Emmanuel Mounier, pasando por la filosofía de la alteridad de Emmanuel Lévinas hasta llegar a la intersubjetividad de Zubiri, dan muestras de cómo el hombre puede ser entendido como ser de relaciones. Cfr. E. MOUNIER, El personalismo. Antología esencial, Salamanca: Sígueme, 2002; W.H. ADAMCZEWLKI, Il significato del dialogo nell 'incontro interumano alla luce della filosofia di Levinas, Roma: Editrice PUG, 2007; J.A. CID, La intersubjetividad en Xavier Zubiri, Roma: Editrice PUG, 2006.

72. A. BANDERA, Comunión eclesial y humanidad, Salamanca: San Esteban, 1978,17, citando a E. Corecco.

73. Ibid., 18. Cfr. también J.-M. R. TILLARD, Carne della Chiesa carne di Cristo, Colonia: Qiqajon, 2006, 46, quien desde una clara eclesiología de comunión afirma: «Los creyentes que el Señor resucitado reúne en el fuego del Espíritu son frente a Dios un sólo corazón y una sola alma en la fe y en la oración, en el compartir los bienes espirituales y materiales, en las relaciones sociales de fraternidad que representan una exigencia del Reino. Su solidaridad viviente (koinonía) es realización del ágape, pero en una forma extremadamente concreta, en la cual la relación con Dios (que es primaria y determinante) no es nunca desligada de la relación con los otros».

74. Cfr. JUAN PABLO II, Ecclesia in America (1999), 52: «La conciencia de la comunión con Jesucristo y con los hermanos, que es, a su vez, fruto de la conversión, lleva a servir al prójimo en todas sus necesidades, tanto materiales como espirituales, para que en cada hombre resplandezca el rostro de Cristo. Por eso, "la solidaridad es fruto de la comunión que se funda en el misterio de Dios uno y trino, y en el Hijo de Dios encarnado y muerto por todos. Se expresa en el amor del cristiano que busca el bien de los otros, especialmente de los más necesitados"». 
conocido como fenómeno de la globalización ${ }^{75}$. Este fenómeno, que si bien es cierto actualmente tiene sólo los rasgos comunicacionales, económicos y culturales, representa el más genuino y profundo anhelo humano de vivir en comunión ${ }^{76}$. Por tanto, la Iglesia, signo e instrumento de la comunión de los hombre entre sí, puede y debe ejercer un rol fundamental en este dinamismo sociológico actual.

Por último, hay que reconocerlo, es innegable la necesidad de comunión entre los creyentes. Los esfuerzos ecuménicos no deben cesar. En el último siglo ha habido grandes avances, pero el camino por recorrer es todavía largo ${ }^{77}$. Además, junto al desafío de la comunión al interno de los creyentes en Cristo existe el reto de entrar en diálogo con las otras religiones ${ }^{78}$. El sentimiento religioso es común a todo ser humano, pero las diferencias en cómo expresar y vivir ese sentimiento son innegables. Por tanto, la Iglesia, instrumento de la comunión entre los hombres, puede y debe ofrecer su humilde servicio de mediadora para alcanzar esa gran comunión querida y suplicada por Jesús: «Padre que todos sean uno» $(\mathrm{Jn} 17,21)^{79}$.

\subsection{Comunión de los hombres con la creación}

A la comunión con Dios y con los demás hombres hay que agregar la comunión con la creación. Pues el hombre es un ser situado y su sitio está en medio de la creación. Es «en este mundo, durante la historia terrena, que el cielo se prepara», dirá Congar ${ }^{80}$. Por eso el hombre debe establecer una relación respetuosa y responsable con el mundo creado. Es más, «la creación entera gime hasta el momento y sufre dolores de parto en espera de la revelación gloriosa de los hijos de Dios» $(\mathrm{Rm} 8,19)$. «Vendrá un día el sábado de Dios: un día del Señor, en una tierra nueva, trasformada plenamente en la tierra del Señor. Dejaremos de llevar a cabo obras que solo eran nuestras obras y que nos atribuíamos, para saber y reconocer que Dios lleva a cabo todo el bien, para dejarle finalmente ser plenamente Dios, es decir, actuar de forma soberana» ${ }^{81}$.

75. Cfr. R. PAPINI, dir., Claves de la globalización, Madrid: Ediciones Palabra, 2004, 94-113.

76. J.-J. TAMAYO-ACOSTA, dir., Diez palabras clave sobre globalización, Navarra: EDV, 2002, 358-395. 77. A. GARUTI, Saggi di ecumenismo, Roma: Antonianum, 2003, 15-17. Con la Conferencia Misionera Mundial, en Edimburgo (1910), inicia este movimiento el cual irá evolucionando progresivamente. A nivel de la Iglesia católica se creó el Secretariado para la unidad de los cristianos (1960), convertido después en el Pontificio consejo para la promoción de la unidad de los cristianos (1988).

78. Cfr. Y. CONGAR, Verdad y dimensiones de la salvación, 231. Cfr. también PONTIFICIO CONCILIO PER IL DIALOGO INTERRELIGIOSO, Dialogo interreligioso nell 'insegnamento ufficiale della Chiesa Cattolica dal Concilio Vaticano II a giovanni Paolo II (1963-2005), Vaticano: Edictrice Vaticana, 2006. 79. Es necesario recalcar que en Y. Congar tenemos un pionero del ecumenismo dentro de la Iglesia. Su programática obra Les chrétiens désunis (1937) delinea lo que posteriormente será el más apasionado teólogo ecuménico católico, ya que como él mismo lo afirma su «vocación eclesiológica y ecuménica surgió en 1929 y 1930, durante el año de mi preparación al sacerdocio»; es decir, estamos ante un estudioso que se siente interiormente llamado a cumplir claramente esa misión teológica dentro de la Iglesia. Cfr. Y. CONGAR, Diario de un teólogo (1946-1956), Madrid: Trotta, 2004, 25.

80. Y. CONGAR, Verdad y dimensiones de la salvación, 96.

81. Ibid., 99. 
Efectivamente, «el hombre no se salva sólo, como individuo desconectado de las demás criaturas, sino más bien como parte de una colectividad humana y un totum cósmico. Así, su plenitud final como persona sólo es imaginable como un misterio de comunión»82.

Si el hombre tiene un destino inseparable con la creación, ya que el proceso salvífico diseñado por Dios afecta todo lo creado, los esfuerzos por cuidar de la casa que Dios nos ha regalado (ecología), mientras estamos en camino a la patria definitiva, nunca serán suficiente. Ciertamente «los cielos son del Señor, la tierra se la dio a los hombres» $($ Sal 115,16$)$, pero como dice Congar, debemos «aprender a ver el mundo como un mundo que tiene por principio el corazón y las manos del Padre, y como fin sus brazos y su corazón. No solamente como un mundo del hombre, ni tampoco como un mundo solo para sí» ${ }^{83}$.

La humanidad necesita aprender a vivir en comunión con lo creado ${ }^{84}$. Por eso la Iglesia, pueblo mesiánico-instrumento de comunión, también debe pontificar esa comunión, hasta «cuando la realidad creada cobre su cabal estatura: cuando Cristo, en la majestad de su gloria, lleve el reino de Dios a su plenitud con el juicio escatológico, la resurrección de los muertos y los cielos y la tierra nuevos, de modo que toda la creación conozca su pascua» ${ }^{85}$. Debe además velar para que se respete una genuina y equilibrada autonomía de las realidades terrenas, como bien lo reconoce y pide la Gaudium et Spes:

Si por autonomía de la realidad se quiere decir que las cosas creadas y la sociedad misma gozan de propias leyes y valores, que el hombre ha de descubrir, emplear y ordenar poco a poco, es absolutamente legítima esta exigencia de autonomía. No es sólo que la reclamen imperiosamente los hombres de nuestro tiempo. Es que además responde a la voluntad del Creador. Pues, por la propia naturaleza de la creación, todas las cosas están dotadas de consistencia, verdad y bondad propias y de un propio orden regulado, que el hombre debe respetar con el reconocimiento de la metodología particular de cada ciencia o arte. Por ello, la investigación metódica en todos los campos del saber, si está realizada de una forma auténticamente científica y conforme a las

82. J.J. ALVIAR, Escatología. Balance y perspectivas, Madrid: Cristiandad, 2001, 127. J. Ratzinger, por su parte, y siempre en términos escatológicos, había afirmado: «Repitamos para finalizar que la salvación del individuo es total y plena sólo cuando se haya alcanzado la salvación del universo y de todos los elegidos», Cfr. J. RATZINGER, Escatología, Barcelona: Herder, 2007 [1977], 254.

83. Y. CONGAR, Verdad y dimensiones de la salvación, 95. Antes había afirmado: «Tantos hombres que no niegan la existencia de Dios, sin embargo son, en la práctica, ateos, en el sentido de que usan la tierra como si Dios no existiese», Ibid., 93-94.

84. Ese aprendizaje es la apuesta del Papa Francisco con su encíclica Laudato si', donde propone los ejes fundamentales para aprender a “cuidar la casa común” bajo la perspectiva de una gran interrelación que existe entre el hombre, Dios y la creación. Cfr. FRANCISCO, Laudato si (2015). 85. J.L. RUIZ DE LA PEÑA, La pascua de la creación, Madrid: BAC, 2000, 123. 
normas morales, nunca será en realidad contraria a la fe, porque las realidades profanas y las de la fe tienen su origen en un mismo Dios ${ }^{86}$.

Ciertamente que como el mismo documento advierte, «si autonomía de lo temporal quiere decir que la realidad creada es independiente de Dios y que los hombres pueden usarla sin referencia al Creador, no hay creyente alguno a quien se le oculte la falsedad envuelta en tales palabras» ${ }^{87}$.

En definitiva, la Iglesia, pueblo de Dios, signo e instrumento de comunión, tiene una gran misión que realizar en el campo del diálogo con las realidades de este mundo. Ser canal de comunión con todas estas realidades, no dudamos en afirmarlo, es también la vocación más profunda de la Iglesia. Y parafraseando la expresión del Papa Pablo VI podemos decir que ser instrumento de comunión constituye, en efecto, la dicha y vocación propia de la Iglesia, su identidad más profunda. Ella existe para unir, es decir, ser canal del don de la gracia divina ${ }^{88}$.

\section{Conclusión}

Definir la identidad de la Iglesia no es fácil. Una definición unívoca sería falsa o por lo menos incompleta. Por eso a lo largo de este trabajo hemos manejado la comprensión de la Iglesia como «misterio de salvación» (a la luz del capítulo I de la Lumen Gentium) y como «pueblo de Dios» (siguiendo el capítulo II). Pero el concilio ofreció un documento en el que se define a la Iglesia como «servidora del mundo», en cuanto que tiene una misión que cumplir en esta historia (hablamos de la Constitución Pastoral Gaudium et Spes). La Iglesia, por tanto, está en el mundo como pueblo de Dios para ser sacramento universal de salvación.

Servir al mundo ofreciéndole la salvación de Cristo es la misión de la Iglesia. Esa misión nace de su identidad. La Iglesia es, por tanto, mediadora de la salvación de Cristo. Nuestro interés ha sido ahondar y describir cómo la Iglesia mediatiza esa salvación, entendida esta como unión con Dios (vida) y unión con los demás (comunión). Por eso, iniciamos nuestra argumentación con la convicción de que la Iglesia se hace instrumento de salvación sirviendo a la vida y posibilitando la comunión. Argumentamos que el modo más adecuado y pertinente que tiene la Iglesia para servir a la vida es a través de los signos sagrados (sacramentos específicos) con que celebra y actualiza la salvación de Cristo.

Los sacramentos, al ser celebraciones actualizantes de la salvación, no deben celebrarse como ritos vacíos, desligados de la vida y alejados de los compromisos

86. GS, n. 36.

87. Ibid.

88. Cfr. PABLO VI, Evangelii Nuntiandi (1975), 14. El Papa habla evidentemente sobre la tarea evangelizadora de que por antonomasia también identifica a la Iglesia. 
más urgentes que mejoran la existencia humana. Los compromisos históricos deben alimentarse a través de la profunda vivencia de los sacramentos, puesto que ellos dan la vida, la curan y la sirven. El ritualismo y rubricismo minimalista con que generalmente son celebrados los sacramentos, opacan y desnaturalizan la gran fuerza salvadora que ellos contienen. Ello exige una profunda revisión de la pastoral sacramental en la Iglesia, y sobre todo una más clara y profunda comprensión de la teología sacramental que debe ofrecerse a la nueva generación de cristianos.

La Iglesia mediatiza la salvación siendo instrumento de comunión. Dicha comunión la hemos orientado hacia tres horizontes: Dios, los demás y el mundo. Posibilitar la comunión con Dios es la más importante misión de la Iglesia, de ahí le nace su identidad sacramental y su estructura condensada en los siete ritos sacramentales. De estos ritos hemos concentrado la atención al sacramento de la Eucaristía, que es el sacramento de comunión con Dios por excelencia. En la primera parte argumentamos que esta comunión con Dios es la que hace posible la vida plena para el hombre.

Pero la Iglesia tiene la misión de unir a los hombres entre si. El hombre es ser de relaciones, necesita establecer sólidos vínculos interpersonales. Sin embargo, la comunión humana es tarea siempre pendiente para la Iglesia, pues no siempre se historiza esa innata necesidad del hombre. Por eso es que la Iglesia siempre ha tenido la conciencia de ser mediadora de conflictos, posibilitadora de diálogos, servidora de la comunión. No es extraño que la Iglesia se ofrezca o sea llamada a tareas delicadas de mediación, podríamos decir que es su especialidad. La comunión debe también reflejarse internamente entre los que cree en Cristo, por eso la Iglesia debe abanderar el esfuerzo del diálogo ecuménico. Lo mismo ha de suceder con el diálogo interreligioso. Todo miembro de la Iglesia ha de tener una arraigada actitud dialogante y conciliadora. Sincretismos y sectarismos no caben en la Iglesia.

Por último, hemos visto que la Iglesia tiene la misión de posibilitar la comunión del hombre con la misma creación. En esta línea es paradigmática la extraordinaria encíclica Laudato si `, del Papa Francisco. Este documento ha venido a poner las sólidas bases para que esa relación con la naturaleza sea responsable, armoniosa y rica para el hombre. El Papa apela a la responsabilidad al invitarnos a «cuidar la casa común»; nos pide además tratar la naturaleza con delicadeza y respeto, ya que estamos plenamente interrelacionados con toda la creación, y perder esa armonía es atentar contra nosotros mismos. Además, puesto que la creación es nuestra casa, debemos disfrutar de lo mejor de ella, mantenerla siempre bella e íntegra para que gocemos de sus innumerables beneficios. Sin duda este documento es pionero de otros que el magisterio de la lglesia deberá ofrecer sobre esta temática, para que con una doctrina tal, todos los cristianos tomemos conciencia de que como Iglesia somos mediadores de una sana relación-comunión del hombre con la naturaleza. 


\section{Bibliografía}

Adamczewlki, W.H., Il significato del dialogo nell'incontro interumano alla luce della filosofia di Levinas, Roma: Editrice PUG, 2007.

Aliotta, M., Il matrimonio, Brescia: Queriniana, 2002.

Alviar, J.J., Escatología. Balance y perspectivas, Madrid: Cristiandad, 2001.

Arnau, R., Tratado general de los sacramentos, Madrid: BAC, 1994.

Arnau, R., Orden y Ministerios, Madrid: BAC, 1995.

Bandera, A., Comunión eclesial y humanidad, Salamanca: San Esteban, 1978.

Blázquez-Ruiz, F. J., dir., 10 palabras claves en nueva genética, Navarra: EVD, 2006.

Boff, L., Los sacramentos de la vida, Santander: Sal terrae, 1991.

Borobio, D., Eucaristía, Madrid: BAC, 2005.

Borobio, D., Sacramentos y etapas de la vida, Salamanca: Sígueme, 2000.

Cid, J.A., La intersubjetividad en Xavier Zubiri, Roma: Editrice PUG, 2006.

Congar, Y., Un pueblo mesiánico. La Iglesia sacramento de salvación, Madrid: Cristiandad, 1976.

Congar, Y., Le vie del Dio vivo, Brescia: Morcelliana, 1965.

Congar, Y., Diario de un teólogo (1946-1956), Madrid: Trotta, 2004.

Ellacuría, I. - Sobrino, J., dirs., Mysterum Liberationis. Conceptos Fundamentales de la Teología de la Liberación, I, Madrid: Trotta, 1990.

Fisichella, R., dir., Catechismo della Chiesa Cattolica,Casale Monferrato: Edizioni Piemme, 2003.

Fitzmyer, J. A., Los hechos de los apóstoles, I, Salamanca: Sígueme, 2003.

Flecha Andrés, J.R., Teología moral fundamental, Madrid: BAC, 1994.

Flórez, G., Penitencia y Unción de enfermos, Madrid: BAC, 1993.

Flórez, G., Matrimonio y Familia, Madrid: BAC, 1995.

Fontbona, J., Comunión y sinodalidad, Barcelona: Facultat de Teologia de Catalunya, 1994.

Forte, B., La Chiesa nell'Eucaristia per un'ecclesiologia eucaristica alla luce del Vaticano II, Napoli: D'Auria, 1975.

Gamarra, S., Teología espiritual, Madrid: BAC, 1994.

Garuti, A., Saggi di ecumenismo, Roma: Antonianum, 2003.

Giraudo, C., In unum corpus. Trattato mistagogico sull'eucaristia, Milano: San Paolo, 2001.

Grillo, A., Grazia visibile, Grazia vivibile. Teologia dei sacramenti «in gere ritus», Padova: Messaggero, 2008.

Grillo, A. - Perioni, M.- Tragan, R., eds., Corso di Teología Sacramentaria, I-II, Brescia: Queriniana, 2000.

Gronchi, M., Trattato su Gesù Cristo figlio di Dio salvatore, Brescia: Queriniana, 2008

Illanes, J.L. - Saranyana, J.I., Historia de la teología, Madrid: BAC, 1995.

Lauret, B.- Refoule, F., dirs., Iniciación a la práctica de la teología, III, Madrid: Cristiandad, 1985.

Louay, S., Santificazione e valore salvifico del matrimonio, Tesi PUG 1433 (2008).

Martínez Sierra, A., 100 Fichas sobre temas controvertidos del sacramento de la reconciliación, Burgos: Monte Carmelo, 2008.

Mondin, B., La Chiesa primizia del regno, Bologna: Deoniano, 1986. 
Mounier, E., El personalismo. Antología esencial, Salamanca: Sígueme, 2002.

Nicolau, M., La unción de los enfermos. Estudio histórico-dogmatico, Madrid: BAC, 1975.

Papini, R., dir., Claves de la globalización, Madrid: Ediciones Palabra, 2004.

Pecklers, K., Liturgia en Contexto, Caracas: Paulinas, 2007.

Pontificia Comisión pro América Latina, Aparecida 2007. Luces para América Latina, Vaticano: Editrice Vaticana, 2008.

Rahner, K., La Iglesia y los Sacramentos, Barcelona: Herder, 1967.

Ratzinger, J., El nuevo pueblo de Dios, Barcelona: Herder, 1972 [1969].

Ratzinger, J., Escatología, Barcelona: Herder, 2007 [1977].

Rodríguez, M. R., El presbiterio y la fraternidad sacerdotal, Madrid: BAC, 2008.

Ruiz de la Peña, J.L., La pascua de la creación, Madrid: BAC, 2000.

Schillebeeckx, E., Cristo, Sacramento del encuentro con Dios, San Sebastián: Dinor, 1963.

Schnackenburg, R.,-Dupont, J., «Boletines. La Iglesia como pueblo de Dios», Concilium 1(1965).

Tamayo-Acosta, J.-J., dir., Diez palabras clave sobre globalización, Navarra: EDV, 2002.

Tangorra, G.- Vergottini, M., eds., Sacramento e azione, Milano: Glossa, 2006.

Tillard, J.-M. R., Carne della Chiesa carne di Cristo, Colonia: Qiqajon, 2006. 